\title{
Fluorescence cholangiography during laparoscopic cholecystectomy in a patient with situs inversus totalis: a case report and literature review
}

\author{
Narongsak Rungsakulkij ${ }^{*}$ id and Pongsatorn Tangtawee
}

\begin{abstract}
Background: Situs inversus totalis is a rare autosomal disorder in which the patient's affected visceral organs are a perfect mirror image of their normal positions. Surgery in these patients is technically challenging. Minimally invasive surgery such as laparoscopic cholecystectomy is the standard treatment for symptomatic cholelithiasis, but it can be difficult to perform. Laparoscopic cholecystectomy in patients with situs inversus totalis may be even more technically challenging. Fluorescence cholangiography is a new innovation in the field of navigation surgery. This procedure is safe and easy to perform, its findings are easy to interpret, and it does not require a learning curve or radiographs. It can be used in real time during surgery to identify extrahepatic biliary structures.

Case presentation: We herein report a case of situs inversus totalis in a Thai patient with a history of biliary pancreatitis. He underwent laparoscopic cholecystectomy with intraoperative fluorescence cholangiography. The operation was successfully completed without complications. To the best of our knowledge, this is the first case report of the use of fluorescence cholangiography during laparoscopic cholecystectomy in a patient with situs inversus.

Conclusion: Fluorescence cholangiographyis a new navigational surgical technique with which to identify extrahepatic biliary structures. It can be used as an adjunct technique during laparoscopic cholecystectomy to avoid biliary tract injury in difficult cases.
\end{abstract}

Keywords: Situs inversus, Situs inversus totalis, Laparoscopic cholecystectomy, Fluorescence cholangiography, Cholelithiasis

\section{Background}

Situs inversus totalis (SIT) is a rare autosomal recessive disorder with an incidence of 1 in 5000 to 20,000 live births. The anatomy of patients with SIT is a perfect mirror image of the normal positions of their visceral organs [1].

Surgery in patients with SIT is technically challenging. Minimally invasive surgery such as laparoscopic cholecystectomy (LC) is the standard treatment for symptomatic cholelithiasis and may be difficult to perform. However, LC in patients with SIT may be even more technically challenging [2-6]. Although many previous

\footnotetext{
* Correspondence: narongsak.run@mahidol.ac.th

Department of Surgery, Faculty of Medicine, Ramathibodi Hospital, Mahidol University, Bangkok 10400, Thailand
}

(c) The Author(s). 2017 Open Access This article is distributed under the terms of the Creative Commons Attribution 4.0 International License (http://creativecommons.org/licenses/by/4.0/), which permits unrestricted use, distribution, and reproduction in any medium, provided you give appropriate credit to the original author(s) and the source, provide a link to the Creative Commons license, and indicate if changes were made. The Creative Commons Public Domain Dedication waiver (http://creativecommons.org/publicdomain/zero/1.0/) applies to the data made available in this article, unless otherwise stated. case reports have described the performance of LC in patients with situs inversus no standard technique has been established for these patients.

Optical or real-time surgery is being increasingly reported in the literature $[7,8]$. One technique used in optical surgery is fluorescence cholangiography (FC) [9]. This method involves the administration of indocyanine green (ICG) by intravenous injection $30 \mathrm{~min}$ before surgery. ICG is taken up by the liver then excreted exclusively in the bile. The excitation of protein-bound ICG by near-infrared light causes it to fluoresce, thereby delineating components of the biliary system for the surgeon. Fluorescence and imaging is achieved through a system comprising a small control unit, a charge- 
coupled device camera, a xenon light source, and a 10-mm laparoscope containing specially coated lenses that transmit near-infrared light. FC is a feasible, low-cost, expeditious, useful, and effective imaging modality. Additionally, it is safe and easy to perform, its findings are easy to interpret, and it does not require a learning curve or radiographs. FC can be used during surgery to identify extrahepatic biliary structures $[10,11]$.

We herein report a case of cholelithiasis in a Thai patient with SIT who presented with a history of biliary pancreatitis. FC was performed during LC. To the best of our knowledge, this is the first such case reported in the literature.

\section{Case presentation}

A 32-year-old man was referred to our hospital for further treatment. He had a known history of SIT. He had been admitted to the previous hospital with acute abdominal pain, and biliary pancreatitis was diagnosed. Ultrasonography showed multiple small gallstones. He was treated conservatively until clinical improvement was noted. After discharge, he was referred to our hospital. In our outpatient clinic, he was well with no fever, abdominal pain, or jaundice.

\section{Investigation}

The results of laboratory investigations, including liver function tests, were normal. A chest radiograph showed dextrocardia, confirming the presence of situs inversus (Fig. 1). He then underwent magnetic resonance

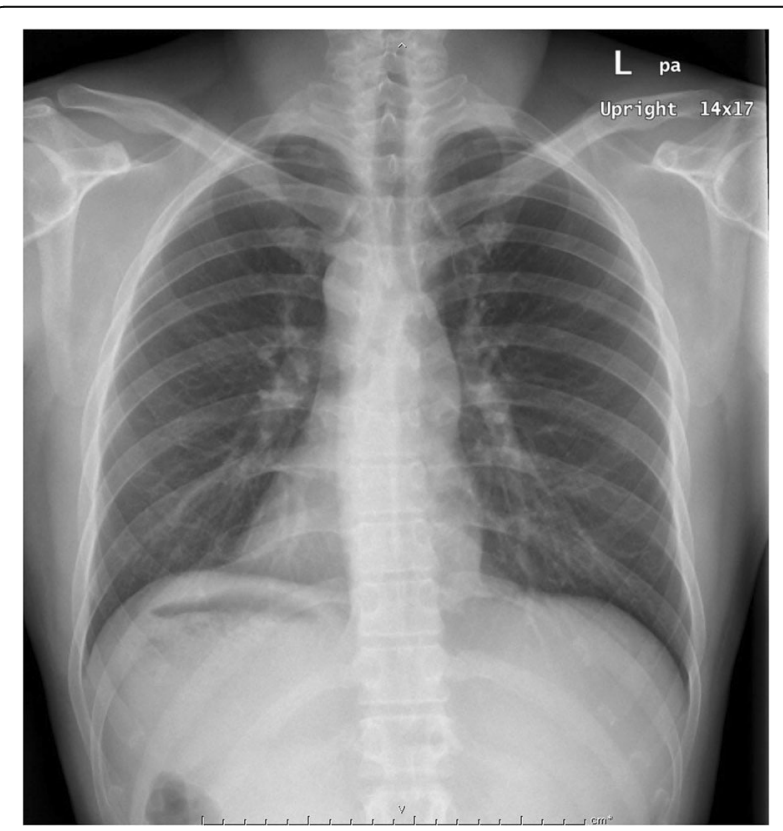

Fig. 1 Chest radiograph findings. Dextrocardia is evident cholangiopancreatography for evaluation of the common bile duct. Although no common bile duct stones were found, a mirror image of the intra-abdominal organs was evident, confirming SIT (Fig. 2). The gallbladder was situated on the left side. The patient was scheduled for elective LC.

\section{Management}

During the operation, the patient was placed in the supine position near the right edge of the operative bed instead of the usual left side. The surgeon stood at the right side of the patient with the camera assistant, and the first assistant stood on the left side. The surgical incision was performed as shown in Fig. 3. A $12-\mathrm{mm}$ subumbilical trocar was inserted by the open technique, and pneumoperitoneum was then established with carbon dioxide gas. A $0^{\circ}$ laparoscope was inserted as shown in the video and three additional ports were inserted under direct vision. The first assistant then grasped the fundus of the gallbladder and retracted it cranially. Before dissection, we performed FC to identify the biliary tree as shown in the video fluorescent light was observed in the gallbladder and common bile duct. The infundibulum was then retracted laterally by the surgeon's left hand. Dissection was performed to identify Calot's triangle, and FC was repeated. We were able to identify the common bile duct, cystic duct, and cystic artery. No abnormal fluorescent light was present in the area between the cystic duct and liver edge. The cystic duct and artery were then individually clipped and safely divided, and the gallbladder was dissected from the liver bed by electrocautery. Hemostasis was performed, and the gallbladder was removed in a retrieval bag through the camera port. The operative time was $45 \mathrm{~min}$. The patient recovered uneventfully and was discharged from hospital the day after the operation.

\section{Discussion}

LC is the standard treatment for symptomatic cholelithiasis. In patients with SIT, however, LC is often technically demanding. Because of the unusual orientation, especially for right-handed surgeons, bile duct injury may easily occur [12]. Many previous reports have described LC in patients with SIT, but no standard techniques have been established for these patients [2-6].

Since Campos and Sipes [13] first reported LC in a patient with SIT in 1991, more than 50 cases of LC in patients with SIT have been reported without complications, even in patients with acute cholecystitis $[2-4,14,15]$. Thus, LC is not contraindicated in patients with SIT. However, such patients are at higher 


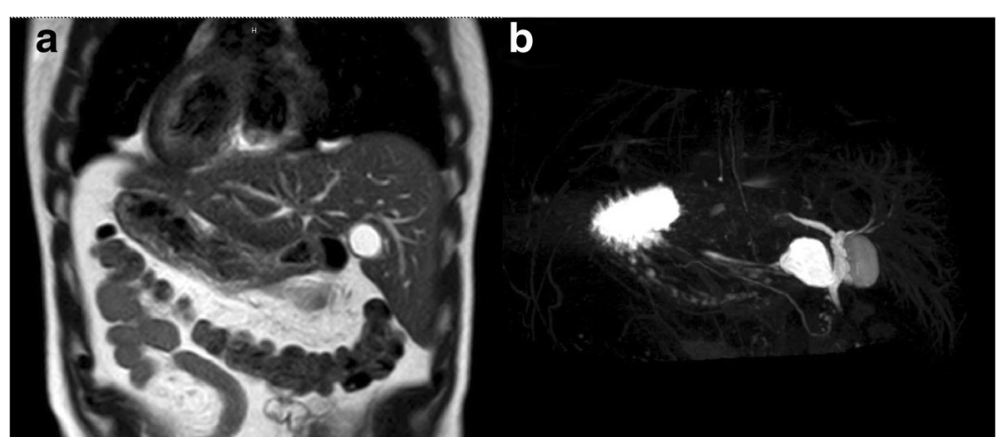

Fig. 2 a Coronal T2W show mirror image of visceral organs. b Magnetic resonance cholangiopancreatography show the gallbladder is present on the left side of the abdominal cavity

risk of complications because the mirror image of the anatomy is an unusual orientation [16]. Most previous reports have concluded that LC in patients with SIT is technically challenging and requires surgeons who are experienced in laparoscopic procedures and hepatobiliary surgery [3-6].

The most common surgical technique used by right-handed surgeons is the four-port technique with an incision created as a mirror image of the conventional incision $[6,17,18]$. The surgeon stands on the

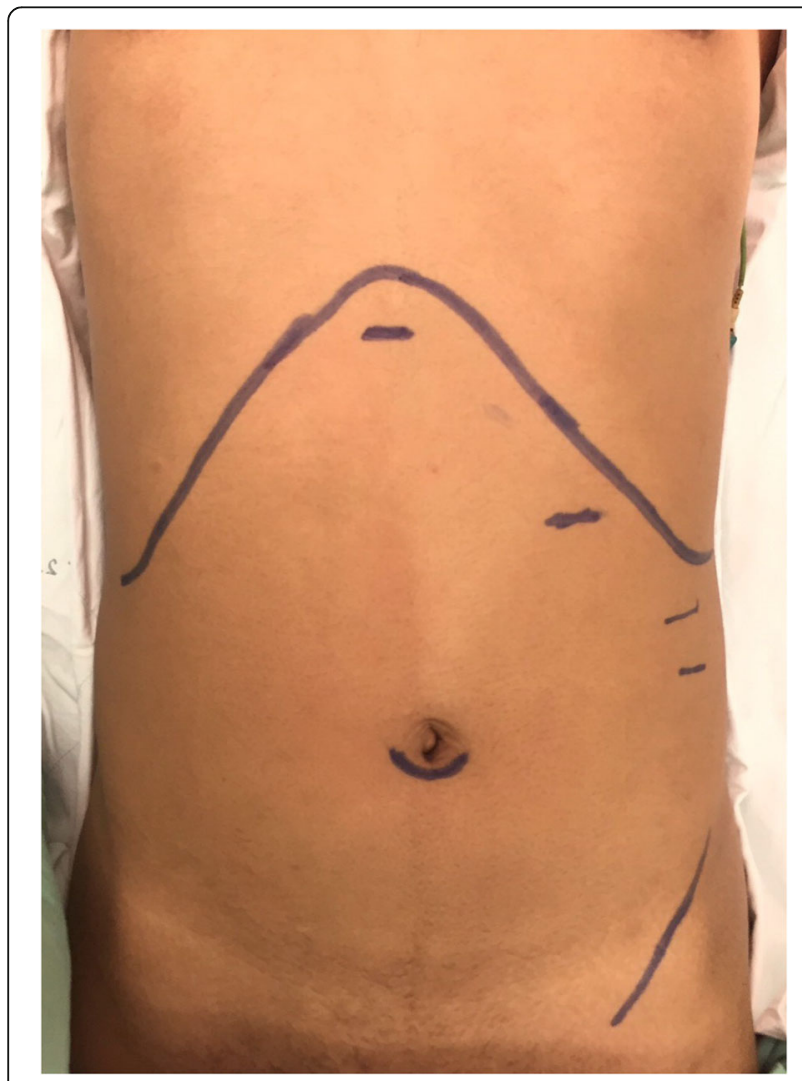

Fig. 3 Locations of port insertion right side of the patient, the first assistant stands on the left side, and the camera assistant stands on the right side next to the surgeon. Left-handed instruments are used to grasp Hartmann's pouch, and the right hand is used in the mid-clavicular port for dissection $[3,18]$.

FC is a recent innovation in optical surgery. ICG is intravenously injected about 15 to $30 \mathrm{~min}$ before the operation, and a special laparoscope containing specially coated lenses that transmit near-infrared light is used. FC is a feasible, low-cost, expeditious, useful, and effective imaging modality. It is safe and easy to perform, and its results are easy to interpret. Many previous reports have described the use of FC during LC to visualize the extrahepatic biliary anatomy and help to avoid bile duct injury [9-11]. This technique has been proven feasible, repeatable, and inexpensive [11]. The critical point in performing LC in patients with SIT is similar to that in patients without SIT; namely, that the critical view of safety must be identified $[16,19,20]$. In the present case, FC was used as a guidance technique with which to identify the biliary tree during the operation, especially at Calot's triangle. This allowed for identification of the critical view of safety, making the operation less difficult. In such cases of difficult LC, as in patients with SIT, FC would be very helpful for surgeons to delineate the extrahepatic biliary tract. Even for less experienced surgeons, the use of FC guidance during careful dissection of Calot's triangle could help to avoid biliary injury.

\section{Conclusion}

LC in patients with SIT is a technically challenging procedure that requires an experienced surgeon. FC is a new navigational surgery technique that can be used to examine the extrahepatic biliary tree and serve as an adjunct during LC in difficult cases, helping to avoid biliary tract injury. 


\section{Additional file}

Additional file 1: Laparoscopic cholecystectomy in situs inversus totalis patient with using fluorescence cholangiography during the operation.

\section{Abbreviations}

FC: Fluorescence cholangiography; ICG: Indocyanine green; LC: Laparoscopic cholecystectomy; SIT: Situs inversus totalis

\section{Acknowledgements}

The authors thank KOSIN Medical Supply Co., Ltd. for contributing the fluorescence equipment.

\section{Funding}

The authors declare that they received no funding.

\section{Availability of data and materials}

The data are available from the corresponding author upon reasonable request.

\section{Authors' contributions}

RN collected the patient's clinical data, analyzed the data, and majorly contributed to the writing of the manuscript; TP wrote the manuscript. Both authors read and approved the final manuscript.

\section{Competing interests}

The authors declare that they have no competing interests.

\section{Consent for publication}

Written informed consent was obtained from the patient for publication of this case report.

\section{Ethics approval and consent to participate}

Not applicable.

\section{Publisher's Note}

Springer Nature remains neutral with regard to jurisdictional claims in published maps and institutional affiliations.

Received: 8 February 2017 Accepted: 11 April 2017

Published online: 20 April 2017

\section{References}

1. Roy A, Crawford JM, Finegold MJ. Inherited metabolic and developmental disorders of the pediatric and adult liver. In: Odze RD, Goldblum JR, editors. Surgical Pathology of the Gl Tract, Liver, Biliary Tract and Pancreas, Third Edition. Philadelphia: Elsevier; 2015. P. 1475-1538.

2. Ahmed Z, Khan SA, Chhabra S, Yadav R, Kumar N, Vij V, Saxena D, Talera D, Kankaria J, Gupta S, Bugalia RP, Goyal A, Yadav BL, Jenaw RK. Our experience with surgery in situs inversus: open peptic perforation repair and laparoscopic cholecystectomy in 1 patient and 3 patients respectively. Int J Surg Case Rep. 2016:29:34-8.

3. Phothong N, Akaraviputh T, Chinswangwatanakul V, Trakarnsanga A. Simplified technique of laparoscopic cholecystectomy in a patient with situs inversus: a case report and review of techniques. BMC Surg. 2015. doi:10. 1186/s12893-015-0012-6.

4. Fang JF, Zheng ZH, Wei B, Chen TF, Lei PR, Huang JL, Huang LJ, Wei HB. Laparoscopic resection for rectal cancer and cholecystectomy for patient withsitus inversus totalis. J Minim Access Surg. 2015;11:210-2.

5. Aydin U, Unalp O, Yazici P, Gurcu B, Sozbilen M, Coker A. Laparoscopic cholecystectomy in a patient with situs inversus totalis. World J Gastroenterol. 2006;12:7717-9.

6. McKay D, Blake G. Laparoscopic cholecystectomy in situs inversus totalis: a case report. BMC Surg. 2005. doi:10.1186/1471-2482-5-5.

7. Rosenthal EL, Warram JM, Bland Kl, Zinn KR. The status of contemporary image-guided modalities in oncologic surgery. Ann Surg. 2014;261:46-55.

8. De Boer E, Harlaar NJ, Taruttis A, Nagengast WB, Rosenthal EL, Ntziachristos V, van Dam GM. Optical innovations in surgery. Br J Surg. 2015;102:e56-72.
9. Ishizawa T, Bandai Y, ljichi M, Kaneko J, Hasegawa K, Kokudo N. Fluorescent cholangiography illuminating the biliary tree during laparoscopic cholecystectomy. Br J Surg. 2010;97:1396-77.

10. Kono Y, Ishizawa T, Tani K, Harada N, Kaneko J, Saiura A, Bandai Y, Kokudo $\mathrm{N}$. Techniques of fluorescence cholangiography during laparoscopic cholecystectomy for better delineation of the bile duct anatomy. Medicine (Baltimore). 2015;94:e1005.

11. Pesce A, Piccolo G, La Greca G, Puleo S. Utility of fluorescent cholangiography during laparoscopic cholecystectomy: a systematic review. World J Gastroenterol. 2015;21:7877-83.

12. Way LW, Stewart L, Gantert W, Liu K, Lee CM, Whang K, Hunger JG. Causes and prevention of laparoscopic bile duct injuries analysis of 252 cases from a human factors and cognitive psychology perspective. Ann Surg. 2003:237:460-9.

13. Campos L, Sipes E. Laparoscopic cholecystectomy in a 39-year-old female with situs inversus. J Laparoendosc Surg. 1991;1:123-5.

14. Alsabek MB, Arafat S, Aldirani A. A case report of laparoscopic cholecystectomy in situs inversus totalis: Technique and anatomical variation. Int J Surg Case Rep. 2016;28:124-6.

15. Reddy A, Paramasivam S, Alexander N. Abhilash, Ravisankar V, Thillai M. Management of a patient with situs inversus totalis with acute cholecystitis and common bile duct stones: a case report. Int J Surg Case Rep. 2014;5:821-3.

16. Polychronidis A, Karayiannakis A, Botaitis S, Perente S, Simopoulos C. Laparoscopic cholecystectomy in a patient with situs inversus totalis and previous abdominal surgery. Surg Endosc. 2002:16:1110.

17. Pahwa HS, Kumar A, Srivastava R. Laparoscopic cholecystectomy in situs inversus: points of technique. BMJ Case Rep. 2012. doi:10.1136/bcr-2012-006170.

18. Arya SV, Das A, Singh S, Kalwaniya DS, Sharma A, Thukral BB. Technical difficulties and its remedies in laparoscopic cholecystectomy in situs inversus totalis: a rare case report. Int J Surg Case Rep. 2013;4:727-30.

19. Salama IA, Abdullah MH, Houseni M. Laparoscopic cholecystectomy in situs inversus totalis: Feasibility and review of literature. Int J Surg Case Rep. 2013;4:711-5.

20. Machado NO, Chopra P. Laparoscopic cholecystectomy in a patient with situs inversus totalis: feasibility and technical difficulties. JSLS. 2006;10:386-91.

\section{Submit your next manuscript to BioMed Central} and we will help you at every step:

- We accept pre-submission inquiries

- Our selector tool helps you to find the most relevant journal

- We provide round the clock customer support

- Convenient online submission

- Thorough peer review

- Inclusion in PubMed and all major indexing services

- Maximum visibility for your research

Submit your manuscript at www.biomedcentral.com/submit 